\title{
Dexamphetamine effects on prepulse inhibition (PPI) and startle in healthy volunteers
}

\begin{tabular}{|c|c|}
\hline Journal: & Psychopharmacology \\
\hline Manuscript ID: & Psych-2013-00628 \\
\hline Manuscript Type: & Original Investigation \\
\hline Date Submitted by the Author: & $10-$ Oct-2013 \\
\hline Complete List of Authors: & $\begin{array}{l}\text { Chitty, Kate; Brain and Mind Research Institute, Sydney Medical School } \\
\text { Albrecht, Matthew; Pharmacology, Pharmacy \& Anaesthesiology Unit, } \\
\text { School of Medicine and Pharmacology, Faculty of Medicine, Dentistry \& } \\
\text { Health Sciences, University of Western Australia, Perth, Western Australia, } \\
\text { Australia, } \\
\text { Graham, Kyran; Pharmacology, Pharmacy \& Anaesthesiology Unit, School } \\
\text { of Medicine and Pharmacology, Faculty of Medicine, Dentistry \& Health } \\
\text { Sciences, University of Western Australia, Perth, Western Australia, } \\
\text { Australia, } \\
\text { Kerr, Chantelle; Pharmacology, Pharmacy \& Anaesthesiology Unit, School } \\
\text { of Medicine and Pharmacology, Faculty of Medicine, Dentistry \& Health } \\
\text { Sciences, University of Western Australia, Perth, Western Australia, } \\
\text { Australia, } \\
\text { Lee, Joseph; Centre for Clinical Research in Neuropsychiatry, The } \\
\text { University of Western Australia and Graylands Hospital, Perth, Western } \\
\text { Australia, Australia, } \\
\text { Iyyalol, Rajan; Centre for Clinical Research in Neuropsychiatry, The } \\
\text { University of Western Australia and Graylands Hospital, Perth, Western } \\
\text { Australia, Australia, } \\
\text { Martin-Iverson, Mathew; Pharmacology, Pharmacy \& Anaesthesiology Unit, } \\
\text { School of Medicine and Pharmacology, Faculty of Medicine, Dentistry \& } \\
\text { Health Sciences, University of Western Australia, Perth, Western Australia, } \\
\text { Australia, ; Centre for Clinical Research in Neuropsychiatry, The University } \\
\text { of Western Australia and Graylands Hospital, Perth, Western Australia, } \\
\text { Australia, }\end{array}$ \\
\hline Keywords: & $\begin{array}{l}\text { PREPULSE INHIBITION, SCHIZOPHRENIA, SEX DIFFERENCES, STARTLE, } \\
\text { DOPAMINE }\end{array}$ \\
\hline
\end{tabular}


Title: Dexamphetamine effects on prepulse inhibition (PPI) and startle in healthy volunteers.

\section{Authors:}

Kate Chitty BSc (Hons) $)^{1,2,3}$

Matthew A. Albrecht PhD 1,2,4

Kyran Graham BSc (Hons) ${ }^{1,2}$

Chantelle Kerr BSc (Hons) ${ }^{1,2}$

Joseph W.Y. Lee MBBS, FRANZCP 2,5

Rajan Iyyalol MBBS, MD, DPM, FRANZCP ${ }^{2}$

Mathew T. Martin-Iverson BSc(Hons), $\mathrm{PhD}$ 1,2,5

${ }^{1}$ Pharmacology, Pharmacy \& Anaesthesiology Unit, School of Medicine and Pharmacology, Faculty of Medicine, Dentistry \& Health Sciences, University of Western Australia, Perth, Western Australia, Australia

${ }^{2}$ Centre for Clinical Research in Neuropsychiatry, The University of Western Australia and Graylands Hospital, Perth, Western Australia, Australia

${ }^{3}$ Brain and Mind Research Institute, The University of Sydney, Sydney, New South Wales

${ }^{4}$ School of Psychology and Speech Pathology, Curtin University, Western Australia, Australia

${ }^{5}$ Statewide Neurophysiology Department, Graylands Hospital, Perth, Western Australia, Australia

\section{Corresponding author:}

Mathew T. Martin-Iverson

Pharmacology, Pharmacy \& Anaesthesiology, The University of Western Australia and Graylands Hospital, Perth, Western Australia, Australia

CCRN, UWA,

35 Stirling Highway, M708

Crawley WA 6009

Tel: $\quad+61(8) 9347-6443$

Fax: +61 (8) 9384-5128 
mathew.martin-iverson@uwa.edu.au

\title{
Funding and Disclosure
}

The Authors declare that there is no conflict of interest. We are grateful to the funding support from the National Health \& Medical Research Council [Project 403994], and for the infrastructure support from the North Metropolitan Area Mental Health Services. M.A. Albrecht was the recipient of a Clinical Neurophysiology supplementary scholarship from the Department of Neurophysiology, North Metropolitan Area Health Service - Mental Health and the School of Medicine and Pharmacology of the University of Western Australia during the course of this study. This experiment complied with the current laws of Australia.

\begin{abstract}
Rationale: Amphetamine challenge in rodent prepulse inhibition (PPI) studies has been used to model potential dopamine involvement in effects that may be relevant to schizophrenia, though similar studies in healthy humans have failed to report replicable or robust effects.

Objectives: The present study investigated dexamphetamine effects on PPI in healthy humans with an increased dose and a range of startling stimulus intensities to determine participant's sensitivity and range of responses to the stimuli. Methods: A randomised, placebo-controlled dexamphetamine (0.45 mg/kg, P.O.), double-blind, counterbalanced, within-subject design was used. PPI was measured in sixty-four participants' across a range of startling stimulus intensities, during two attention set conditions (ATTEND and IGNORE). Startle magnitudes for pulse-alone and prepulse-pulse magnitudes were modelled using the startle reflex magnitude (sigmoid) function. Parameters were extracted from these fits, including the upper limit of the asymptote (maximum startle reflex capacity, $\mathrm{R}_{\mathrm{MAX}}$ ), intensity threshold, stimulus intensity that elicits a half-maximal response $\left(\mathrm{ES}_{50}\right)$ and the maximum rate of change of startle response magnitude to an increase in stimulus intensity. Results: Dexamphetamine increased the threshold and $\mathrm{ES}_{50}$ of the response to pulsealone trials in both sexes and reduced $\mathrm{R}_{\mathrm{MAX}}$ exclusively in females. Dexamphetamine modestly increased PPI of the $\mathrm{R}_{\text {MAX }}$ across both attention conditions. PPI of $\mathrm{R}_{\text {MAX }}$ was reduced during the ATTEND condition compared to the IGNORE condition.
\end{abstract}


1

2

3

4

5

6

7

8

9

10

11

12

13

14

15

16

17

18

19

20

21

22

23

24

25

26

27

28

29

30

31

32

33

34

35

36

37

38

39

40

41

42

43

44

45

46

47

48

49

50

51

52

53

54

55

56

57

58

59

60

Conclusions: Results indicate that sex differences exist in motor, but not sensory, components of the startle reflex. Findings also reveal administration of $0.45 \mathrm{mg} / \mathrm{kg}$ dexamphetamine to healthy humans does not mimic PPI effects observed in schizophrenia.

\section{Keywords}

prepulse inhibition, PPI, dopamine, dexamphetamine, attention, schizophrenia 


\section{Introduction}

Hyperactivity of the dopaminergic system is one postulated mechanism for the emergence of the positive symptoms of schizophrenia; also known as the dopamine hypothesis of schizophrenia (Howes and Kapur 2009). This hypothesis is the longest lasting postulated mechanism for schizophrenia, and is supported by several lines of converging evidence. Firstly, all effective antipsychotics reduce activity at dopamine $\mathrm{D}_{2}$ receptors (Seeman et al. 1975; Seeman and Lee 1975; Creese et al. 1976)). Secondly, more dopamine is released in the brains of people with schizophrenia compared with healthy volunteers following amphetamine challenge (Abi-Dargham et al. 1998; Abi-Dargham et al. 2009; Breier et al. 1997; Laruelle et al. 1996) and they show higher basal release of dopamine (Abi-Dargham et al. 2009). Thirdly, dopamine synthesis is higher in people with schizophrenia than in healthy controls (Kumakura et al. 2007).

Reduced prepulse inhibition (PPI) of the startle reflex is consistently reduced in individuals with schizophrenia and their relatives, suggesting that it is an endophenotype of the disorder (Braff et al. 2001; Cadenhead et al. 2000; Parwani et al. 2000; Scholes and Martin-Iverson 2010; Swerdlow et al. 2006; Turetsky et al. 2007). In preclinical research, changes in PPI have become one of the leading nonhuman animal models for schizophrenia, and results from rodent research of PPI have been consistent with the dopamine hypothesis. For example, PPI reductions were observed in rodents following infusions of dopamine (Swerdlow et al. 1990) or dopamine $\mathrm{D}_{2}$ receptor agonists (Wan and Swerdlow 1993) into the nucleus accumbens as well as after systemic injection of dexamphetamine (Mansbach et al. 1988). Furthermore, reductions in PPI that are induced by dopamine agonists can be reversed by administration of haloperidol ( $\mathrm{a}_{2}$-receptor antagonist) or by lesioning the dopaminergic neurons of the ventral tegmental area (Swerdlow et al. 1990).

Currently there is little evidence in humans that strongly implicate dopamine hyperactivity in the PPI deficits observed in people with schizophrenia. An initial paper by Hutchison and Swift (1999) reported a significant reduction of PPI by a low dose of dexamphetamine $(20 \mathrm{mg})$ at 90 minutes post-dose, but not at 60 or 120 minutes post-dose. Similar investigations by Swerdlow's group (Swerdlow et al. 2002; Talledo et al. 2009) with the same dose of amphetamine did not find an effect on PPI. Though in one study (Swerdlow et al. 2003), a modest decrease in PPI was 
observed at 25 minutes post-dose followed by a non-significant increase at the more physiological plausible time of $150 \mathrm{~min}$ post-dose. These inconsistent findings are surprising given dopamine's well-documented association with psychosis and schizophrenia and its status as a strong candidate for the causation of impaired PPI in schizophrenia.

The failure to replicate in humans the relatively consistent disruptive effects of high doses of dexamphetamine on PPI in rodent studies may be driven by a number of methodological limitations. Firstly, previous studies may have had insufficient sample sizes to reliably detect PPI deficits at the dose of dexamphetamine administered. Second, the safe dose of dexamphetamine for humans is much less than the $2-6 \mathrm{mg} / \mathrm{kg}$ doses of dexamphetamine needed to robustly cause disruptions of PPI in rodents (Salum et al. 2006). Thirdly, previous studies have used a single startling stimulus, which does not enable the detection of inter-individual and inter-group differences in sensitivities to startling stimuli. Fourthly, the role of top-down attentional influences on PPI is rarely controlled in PPI experiments and remains an important potential confounder that limits the inferences and interpretations drawn from PPI research (Scholes and Martin-Iverson 2009). Lastly, there have been several observations of sex differences in PPI in healthy humans (Kumari et al. 2004; Swerdlow et al. 1999) and in dopamine neurophysiology (Boudikova et al. 1990; Chen et al. 2004; Floderus et al. 1981) that may interact to substantially affect the relationship between dopamine and PPI.

\section{Aims}

The present study investigated dexamphetamine effects on PPI in healthy humans, while addressing the methodological limitations of previous work. This was achieved by using a wide range of startling stimulus intensities to clearly determine startling stimulus thresholds, potencies $\left(\mathrm{ES}_{50}\right)$, and maximum effects $\left(\mathrm{R}_{\mathrm{MAX}}\right)$ for each individual under each experimental condition. Moreover, we have collected the largest sample size and administered the highest dose of dexamphetamine to be used to date in a human dexamphetamine study of PPI.

\section{Methods}

\section{Participants}

A total of 75 participants were recruited. Of those, three had identified drug use within seven days of testing, one registered baseline hypertension, and seven either had insufficient startle responses or had poor EMG recordings and therefore were 
excluded from analysis. This left a total of 64 participants ( 24 females) in the final analysis. All participants were administered $0.45 \mathrm{mg} / \mathrm{kg}$ (P.O.) dexamphetamine sulphate. Participant demographic characteristics are presented in Table 1. All participants were screened prior to enrolment by the study psychiatrists. Exclusory criteria consisted of previous head injury involving loss of consciousness, current mental illness, family history of schizophrenia, inability to detect the prepulses in a sound detection test and participants taking any medications except for the contraceptive pill. Participants were compensated $\$ 100$ for their time. The study was approved by the University of Western Australia Ethics Committee and the North Metropolitan Area Mental Health Services Human Research Ethics Committee, and was registered with the Australian New Zealand Clinical Trial database, registry numbers ACTRN12608000610336.

\section{Design and Statistical Analysis}

The experiment was a randomised, placebo-controlled, double-blinded, counterbalanced, within-subject study. Participants were required to attend two sessions five to seven days apart (with most at seven). Sessions started at approximately 9:30am. After the consent and physical exam, resting blood pressure (BP) and heart rate (HR) measurement were taken with an Omron M4 digital blood pressure monitor. Participants were then administered placebo or drug. Table 1 outlines the drug order of the participants (i.e. whether they were administered the active pill or placebo in the first session). At 80 min post-ingestion, BP and HR measurements were taken and startle/PPI testing began at 90 min post-ingestion.

First, participants completed the sound detection task to ensure detection of the prepulse. Participants were then assigned an attention order (i.e. whether they completed the ATTEND or IGNORE startle/PPI condition first or second, see Table 1). The ATTEND and IGNORE conditions had two blocks and each block consisted of three trials of each startling stimulus that consisted of white noise pulses ranging in intensity from $80-115 \mathrm{~dB}$ in $5 \mathrm{~dB}$ increments over a $65 \mathrm{~dB}$ white noise background. Two-thirds of these trials were proceeded by a $74 \mathrm{~dB}$ prepulse with stimulus onset asynchrony (SOA) of either $60 \mathrm{~ms}$ or $100 \mathrm{~ms}$. There was also one prepulse alone trial and one null trial in each block. This gave 26 trials per block, totalling 52 trials across the two blocks and took approximately 15 minutes. The stimuli were presented in a random order within each block.

\section{ATTEND and IGNORE conditions}


In the ATTEND condition the participants were instructed to pay close attention to the sounds (pulse only, prepulse + pulse and a null trial) and to press a button corresponding to the number of sounds they heard after each trial. In the IGNORE condition the participants were instructed to ignore the sounds and to count the number of smiley faces hidden within the pictures displayed on the screen. The visual stimuli were chosen from the International Affective Picture System and had neutral pleasantness/unpleasantness ratings and low arousal scores; with average valence and arousal ratings of $4.93(\mathrm{SD}=0.96)$ and $3.77(\mathrm{SD}=1.47)$, respectively. The instructions presented on the screen after the picture was presented asked the participants to press the button corresponding to the number of smiley faces they found from 1-5. The prepulse and stimulus were presented at various times after the picture was presented. The order of attention condition was counterbalanced between participants.

\section{Scoring}

Responses were recorded using a standard National Instruments data acquisition (DAQ) card (DAQ 6062E; San Diego, USA). The stimuli were presented binaurally through a pair of stereo headphones (Sennheiser HD25-1), with $600 \mathrm{~ms}$ of baseline recording before the startle stimulus and $400 \mathrm{~ms}$ after the startle stimulus was presented. The EMG signal was hardware bandpass filtered $(30-500 \mathrm{~Hz})$, and hardware notch filtered at $50 \mathrm{~Hz}$ before being sampled at $1000 \mathrm{~Hz}$. The EMG recordings were further filtered offline ( $78-240 \mathrm{~Hz}$ bandpass plus $60 \mathrm{~Hz}$ notch filter) and rectified before scoring. Scoring was carried out automatically according to predefined criteria: baseline - mean muscle activity in the $600 \mathrm{~ms}$ baseline period; peak magnitude - maximum EMG response recorded between 20-200 ms post-startling stimulus; onset latency - onset of EMG response where the blink crosses the response threshold (defined as 3 SD above the baseline mean) within the 20-200 ms response zone. A scorer blind to drug and stimulus conditions manually checked the accuracy of the automatic detection.

\section{Bayesian non-linear regression curve fitting}

Bayesian hierarchical non-linear regression was used to fit the 3-parameter sigmoidal function shown in equation 1 to the data:

$y=R M A X+\frac{(0-R M A X)}{\left(1+\left(\frac{x}{E S 50}\right)^{h i l l s l o p e}\right.}$

where $\mathrm{y}$ is the startle magnitude, $\mathrm{R}_{\mathrm{MAX}}$ is the upper asymptote, $\mathrm{ES}_{50}$ is the stimulus 
intensity required to produce a half-maximal response, hillslope is the velocity at the $\mathrm{ES}_{50}$, and, because the data were baseline corrected, the y-intercept (or lower asymptote) is set at 0 .

For each individual, an overall curve estimate was fitted for pulse alone and prepulse-pulse conditions. These participant level hyperparameters were described by flat priors on the approximate scale of the coefficients: $\mathrm{R}_{\mathrm{MAX}}=$ Uniform distribution bounded between 0 and $1.5 *$ maximum response for that person; $\mathrm{ES}_{50}=$ Uniform distribution on the log hillslope bounded between 1 and $7 \mathrm{~dB}$; hillslope $=$ Uniform distribution bounded between 2 and 500. The resulting estimates from the higher level curves within each participant informed parameter estimates of the $\mathrm{R}_{\mathrm{MAX}}, \mathrm{ES}_{50}$, and the hillslope for each drug by attention by SOA condition. The lower level priors for $\mathrm{R}_{\mathrm{MAX}}$ and $\mathrm{ES}_{50}$ were described by normal distributions and the hillslope priors described by a lognormal distribution each centred on the higher level estimate with the precisions estimated from Cauchy distributions. Hierarchical models have the advantage of partially-pooling estimates towards each other (shrinkage) which yields more precise and efficient estimates of the parameters of interest (Gelman et al. 2003). In our simulations (see Supplementary Material 1), they consistently outperformed least squares fits. More model fitting details and example fits are presented in Supplementary Material 2.

After 5,000 adaptation steps and 10,000 burn-in steps, a total of 1,000,000 total samples of the posterior were taken, thinned every 20th step giving a total of 50,000 saved samples spread across 3 chains. Convergence was monitored using the GelmanRubin diagnostic (Gelman and Rubin 1992) and more than 99\% of extracted parameters had $>1000$ effective samples.

\section{Analysis}

The median of the posterior parameter estimates of $\mathrm{R}_{\mathrm{MAX}}, \mathrm{ES}_{50}$, and hillslope were used for the analyses. From these estimates an extra parameter "threshold" (the minimum stimulus intensity required to illicit startle) was calculated according to the equation:

Threshold $=E S 50-\frac{R M A X-y 0}{\text { Hillslope }}$

Each parameter was also converted to a PPI measure. PPI of $\mathrm{R}_{\mathrm{MAX}}$ was calculated as follows: $\% P P I=\frac{P(R M A X)-P P(R M A X)}{P(R M A X)} \times 100$ 
where $\mathrm{P}\left(\mathrm{R}_{\mathrm{MAX}}\right)=\mathrm{R}_{\mathrm{MAX}}$ of the pulse alone trials, $\mathrm{PP}\left(\mathrm{R}_{\mathrm{MAX}}\right)=\mathrm{R}_{\mathrm{MAX}}$ of the prepulse + pulse trials $(\mathrm{SOA}=500$ or $540 \mathrm{~ms})$. PPI of $\mathrm{ES}_{50}$, threshold and hillslope were calculated by subtracting the estimate from the prepulse + pulse trials away from the pulse only trials (e.g., $\mathrm{P}\left(\mathrm{ES}_{50}\right)$ - PP(ES$\left(\mathrm{ES}_{50}\right)$ ). Positive PPI of $\mathrm{ES}_{50}$ and threshold values indicate a shift to the right of the curve (see Figure 1). PPI of hillslope was calculated by P (hillslope) - PP (hillslope), so that positive values indicate a flattening of the slope in response to prepulse + pulse trials (as can be seen from Figure 1, hillslope increases during prepulse + pulse trials).

All extracted startle and PPI parameters were entered into a Bayesian linear mixed-effects model using the "MCMCglmm" package and its associated default priors (Markov Chain Monte Carlo generalised linear mixed models; (Hadfield 2010)). Factors entered into the model were sex, drug order, drug condition (placebo vs dexamphetamine), attention, and SOA with participant treated as the random effects term. The mixed-model was run for 2,000,000 iterations, with a burn-in period of 10,000 steps. The posterior was thinned every 10 steps. From the posterior of the mixed-model, means $\pm 95 \%$ highest density intervals (HDI) were used to describe the credible interval for each of the estimates and contrasts.

All statistical analyses were conducted in $\mathrm{R}$ version 2.15.1. The Bayesian hierarchical non-linear fitting was carried out using the "rjags" package (Plummer 2013).

\section{Results}

Autonomic measures

Participants' systolic and diastolic blood pressure and heart rate at baseline were roughly equivalent across placebo and dexamphetamine conditions (mean placebo heart rate $=71.3$, Dex-Pla contrast $=-1.08,95 \%$ HDI $=-3.17,1.01$; mean placebo systolic pressure $=123.5$, Dex-Pla contrast $=0.16,95 \% \mathrm{HDI}=-2.76,3.02$; mean placebo diastolic pressure $=73.0$, Dex-Pla contrast $=-0.046,95 \% \mathrm{HDI}=-1.78,1.71$ ) At 75 and 130 minutes post-dose, the times immediately before and after startle testing respectively, blood pressure and heart rate were substantially elevated by dexamphetamine. At 75 minutes, dexamphetamine increased systolic pressure, diastolic pressure and heart rate by $11.3 \mathrm{~mm} \mathrm{Hg}(95 \% \mathrm{HDI}=5.83,16.6), 7.91 \mathrm{~mm} \mathrm{Hg}$ $(95 \% \mathrm{HDI}=4.25,11.7)$, and $3.32 \mathrm{bpm}(95 \% \mathrm{HDI}=0.77,5.94)$. Similarly at 130 minutes, dexamphetamine increased systolic pressure, diastolic pressure and heart rate by $14.9 \mathrm{~mm} \mathrm{Hg}(95 \% \mathrm{HDI}=8.64,21.1), 7.57 \mathrm{~mm} \mathrm{Hg}(95 \% \mathrm{HDI}=3.87)$, and 8.92 
bpm $(95 \%$ HDI $=4.95,13.0)$, respectively.

\section{Startling pulse alone trials}

Figure 1 illustrates the startle intensity response curves and the contrasts for the main effect of dexamphetamine, main effect of sex, and the interaction between dexamphetamine and sex during the pulse alone trials. Dexamphetamine reduced the $\mathrm{R}_{\text {MAX }}$ (Dexamphetamine - Placebo contrast $=-18.0 \mu \mathrm{V}, 95 \% \mathrm{HDI}=-26.7,-9.54$ ) and increased the $\mathrm{ES}_{50}$ (contrast $\left.=2.46 \mathrm{~dB}, 95 \% \mathrm{HDI}=1.39,3.46\right)$ and threshold (contrast $=1.88 \mathrm{~dB}, 95 \% \mathrm{HDI}=0.65,3.12$ ) parameters during the pulse alone condition. The reduction in $\mathrm{R}_{\mathrm{MAX}}$, but not $\mathrm{ES}_{50}$, was driven by a drug by sex interaction $\left(\mathrm{R}_{\mathrm{MAX}}\right.$ drug by sex interaction contrast $=-28.3 \mu \mathrm{V}, 95 \% \mathrm{HDI}=-44.9,-10.9)$, where dexamphetamine was only effective in reducing the $\mathrm{R}_{\text {MAX }}$ parameter in females but not in males (Figure 1C). No other effects were credibly different to 0 (see Supplementary Material 3).

\section{$P P I$}

Figure 2 illustrates the main effects of dexamphetamine, attention, sex, and SOA on PPI of the $\mathrm{R}_{\mathrm{MAX}}, \mathrm{ES}_{50}$, threshold and hillslope, including the results of the tested contrasts. As can be seen from Figure 2, there was a modest increase in PPI of $\mathrm{R}_{\mathrm{MAX}}$ after dexamphetamine administration (dexamphetamine - placebo contrast $=$ $4.20 \%, 95 \%$ HDI $=0.75,7.74)$.

Attention was also shown to be a modulator of PPI, replicating previous results from our laboratory. Figure 2 demonstrates that PPI of $\mathrm{R}_{\mathrm{MAX}}$ was reduced during the ATTEND condition compared to the IGNORE condition (ATTEND - IGNORE contrast $=-4.61 \%, 95 \%$ HDI $=-8.07,-1.13)$.

Figure 3 presents the interaction between drug and attention. None of the contrasts for this interaction credibly excluded 0 (interaction contrast for PPI of $\mathrm{R}_{\mathrm{MAX}}$ $=-2.02,95 \% \mathrm{HDI}=-8.77,5.15 ; \mathrm{ES}_{50}=-0.29,95 \% \mathrm{HDI}=-1.90,1.25 ;$ threshold $=$ $2.13,95 \%$ HDI $=-4.26,0.086$; hillslope $=0.12,95 \%$ HDI $=-0.32,0.27$ ).

\section{Discussion}

Administration of $0.45 \mathrm{mg} / \mathrm{kg}$ of dexamphetamine to healthy participants reduced the sensitivity of the startle response to pulse-alone trials (increased threshold and $\mathrm{ES}_{50}$ ) in both males and females and reduced the maximum startle response elicited ( $\mathrm{R}_{\mathrm{MAX}}$ ) exclusively in females. In the PPI analysis, dexamphetamine modestly increased PPI of $\mathrm{R}_{\mathrm{MAX}}$. PPI of $\mathrm{R}_{\mathrm{MAX}}$ was also reduced during the ATTEND condition compared to the IGNORE condition, an effect similar to that previously found in 
healthy controls (Scholes and Martin-Iverson 2010).

\section{Startling Pulse Alone trials}

Our study has uncovered interesting differences between males and females in startle amplitudes after dexamphetamine administration. This supports accumulating evidence of sex differences in dopamine neurophysiology (Boudikova et al. 1990; Chen et al. 2004; Floderus et al. 1981) and its modulation of behaviour. A study in healthy humans with no pharmacological manipulation found a consistently higher startle response in females across all blocks (Aasen et al. 2005) which was also demonstrated in females with schizophrenia who displayed greater response amplitude than affected males (Kumari et al. 2004), reflecting the placebo results in the present study. An elevated baseline startle may provide more reduction potential for dexamphetamine in females compared to males. By contrast, a female-specific dexamphetamine-induced reduction in $\mathrm{R}_{\mathrm{MAX}}$ produced by startling pulses alone may be due to a greater shift towards a $\mathrm{D}_{2}$ receptor state in females after dexamphetamine. This is suggested for three reasons. Firstly, research using selective $D_{1}$ and $D_{2}$ receptor agonists have shown that increased $\mathrm{D}_{1}$ receptor activation increases startle (Meloni and Davis 1999), and $\mathrm{D}_{2}$ receptor activation decreases startle (Martin-Iverson and Else 2000). This suggests a $D_{2}$ receptor mediated effect in our females given dexamphetamine. Secondly, findings of greater frontal $\mathrm{D}_{2}$ receptor densities in females (Kaasinen et al. 2001, although see Glenthoj et al. 2006), is also supportive of a relatively stronger $\mathrm{D}_{2}$ receptor mediated effect in females. Thirdly, females have higher striatal presynaptic dopamine synthesis capacity (Laakso et al. 2002), higher endogenous synaptic concentrations of dopamine (Pohjalainen et al. 1998), and higher amphetamine-induced dopamine release within the right globus pallidus and right inferior frontal gyrus (Riccardi et al. 2006). This elevation of baseline dopamine tone may result in an enhanced elevation of synaptic dopamine concentrations leading to more $\mathrm{D}_{2}$ receptors to be activated in response to dexamphetamine in females, pushing the functional brain dopamine state more towards a $\mathrm{D}_{2}$ receptor mediated state (Durstewitz and Seamans 2008).

In addition to the sex-specific effects on the $\mathrm{R}_{\mathrm{MAX}}$ of the startling pulse alone condition, dexamphetamine administration reduced the sensitivity of the startle response (participants became less sensitive to more intense sounds) in both males and females, as indicated by the increase in $\mathrm{ES}_{50}$ and threshold. This provides further evidence that the components of the startle curve are separable and differentially 
effected by pharmacological manipulation. It also provides clearer picture of dexamphetamine action in this context; in males it is reducing the sensitivity of the startle circuit, yet not disrupting the maximum startle. Whilst in females it is reducing startle sensitivity, with a corresponding reduction in maximum startle.

Interestingly, there was no effect of attention or drug by attention interaction on any of the startle measures.

$P P I$

In the present study, dexamphetamine increased PPI of $\mathrm{R}_{\mathrm{MAX}}$ by approximately $4 \%$. This is substantially different to the approximately $13 \%$ reduction at 90 minutes post-dose in Hutchison and Swift (1999) and more similar to the marginal effects reported in Swerdlow et al (2003). Differences between these studies, including the present study, may be attributable to startle effects, not PPI effects, which are modulated by the startling stimulus intensity used. For example, one group used a startling stimulus intensity (118 dB; Swerdlow et al. 2002; 2003) most likely to correspond to the upper asymptote range of the startle curves generated in the present study, while the other study used an intensity (105 dB, Hutchison and Swift 1999) more likely to correspond to the dynamic range (close to the $\mathrm{ES}_{50}$ ) presented here. Given that our study is the largest human amphetamine PPI study ( $\mathrm{n}=64)$, has used the largest dose of dexamphetamine in humans to date $(0.45 \mathrm{mg} / \mathrm{kg})$, has used highly controlled experimental manipulations (variable startling stimuli and attention constraints), and previous research has shown either inconsistent effects or has not demonstrated any strong disrupting effects (Hutchison and Swift 1999; and Swerdlow et al. 2002; 2003) it appears as though the effect of amphetamine on human PPI up to $0.45 \mathrm{mg} / \mathrm{kg}$ is relatively negligible.

In the present experiment, participants showed less PPI of $\mathrm{R}_{\mathrm{MAX}}$ when their attention was directed toward the startling stimuli compared to when attention was diverted away from the startling stimuli. This supports previous reports of attentional modulation of PPI found in controls (Dawson et al. 1993; Scholes and Martin-Iverson 2010). Attention toward the prepulse may reduce the unexpectedness of the startling stimuli and inhibitory potential of the prepulse (Scholes et al. 2010). However, we did not find an effect of attention during the startling pulse alone trials, failing to support the hypothesis that attention toward the stimuli itself might reduce the size of the reflex (Ekman et al. 1985; Foss et al. 1989). People with schizophrenia have generally failed to show attentional modulation of PPI compared to healthy controls (Dawson et 
al. 1993; Dawson et al. 2000; Kedzior and Martin-Iverson 2007; Scholes and MartinIverson 2010). In studies that have explicitly manipulated attention, PPI deficits in schizophrenia have only been observed when controlled selective attention processes are required, suggesting that decreased PPI may be consequent to dysfunctions in selective attention (Dawson et al. 2000; Kedzior et al. 2007). We did not find any effect of dexamphetamine on attentional modulation of PPI, another indication that dexamphetamine administration in healthy humans may not model the PPI deficits observed in schizophrenia at a single dose of $0.45 \mathrm{mg} / \mathrm{kg}$.

That said, the dose of dexamphetamine used in this PPI study (the highest dose given to humans to date in a PPI experiment), is still substantially lower than the minimum dose of $1.0 \mathrm{mg} / \mathrm{kg}$ required to elicit a disruptive effect in rodents (Mansbach et al. 1988) with more robust effects requiring at least $2.0 \mathrm{mg} / \mathrm{kg}$ (Salum et al. 2006). Doses of this magnitude are ethically unviable in human volunteers, so this issue is unlikely to be resolved.

The present study used full stimulus intensity response curves to better account for individual differences in the response to startling stimulus. To a limited extent, this method can be compared to PPI studies that administer single dB levels, regardless of variations across the participant sample in sensitivities to sound and startle responses. The results obtained from the $\mathrm{R}_{\text {MAX }}$ parameter would be closer to those observed after high startle stimulus intensities $>=115 \mathrm{~dB}$, while the $\mathrm{ES}_{50}$ parameter would tend to be more variable as it is the centre of the dynamic range, and this can vary by tens of $\mathrm{dB}$ (several log units) across individuals. Therefore, it is safe to assume that if the intensity of a fixed startling stimulus is below $115 \mathrm{~dB}$, the more people in the sample will be within the dynamic range (Scholes and Martin-Iverson 2009). Researchers should keep this in mind when they make comparisons of this study to the wider literature, or between studies such as the Hutchison \& Swift (1999, with $105 \mathrm{~dB}$ startling stimuli and 50\% females) and the Swerdlow et al (2002, 2003 papers, with $118 \mathrm{~dB}$ startling stimuli and $100 \%$ males).

Dexamphetamine significantly reduced sensitivity to startling stimuli (increased thresholds) and startling stimulus potency (increased $\mathrm{ES}_{50}$ ) in both males and females, and decreased the maximum startle response in females, but not males. These findings support the accumulating evidence of sex differences in dopamine neurophysiology. Dexamphetamine also modestly increased PPI of $\mathrm{R}_{\mathrm{MAX}}$. Given the modest enhancing effect of dexamphetamine on PPI and the lack of a drug by attention interaction in the 
present study, dexamphetamine administration in healthy humans may not be a suitable model of the PPI deficits observed in schizophrenia at the single dose of 0.45 $\mathrm{mg} / \mathrm{kg}$. Larger doses of dexamphetamine may be needed, but this poses a number of ethical considerations that may not be easily overcome in healthy human volunteers.

\section{Acknowledgements}

The authors would like to express their gratitude to individuals who participated in this study.

\section{References}

Aasen I, Kolli L, Kumari V (2005) Sex effects in prepulse inhibition and facilitation of the acoustic startle response: implications for pharmacological and treatment studies. Journal of psychopharmacology (Oxford, England) 19: 3945. doi: 10.1177/0269881105048890

Abi-Dargham A, Gil R, Krystal J, Baldwin RM, Seibyl JP, Bowers M, van Dyck CH, Charney DS, Innis RB, Laruelle M (1998) Increased striatal dopamine transmission in schizophrenia: confirmation in a second cohort. Am J Psychiatry 155: 761-7. doi:

Abi-Dargham A, van de Giessen E, Slifstein M, Kegeles LS, Laruelle M (2009) Baseline and amphetamine-stimulated dopamine activity are related in drugnaive schizophrenic subjects. Biol Psychiatry 65: 1091-3. doi: 10.1016/j.biopsych.2008.12.007

Boudikova B, Szumlanski C, Maidak B, Weinshilboum R (1990) Human liver catechol-O-methyltransferase pharmacogenetics. Clinical pharmacology and therapeutics 48: 381-9. doi:

Braff DL, Geyer MA, Swerdlow NR (2001) Human studies of prepulse inhibition of startle: normal subjects, patient groups, and pharmacological studies. Psychopharmacology (Berl) 156: 234-58. doi:

Breier A, Su TP, Saunders R, Carson RE, Kolachana BS, de Bartolomeis A, Weinberger DR, Weisenfeld N, Malhotra AK, Eckelman WC, Pickar D (1997) Schizophrenia is associated with elevated amphetamine-induced synaptic dopamine concentrations: evidence from a novel positron emission tomography method. Proc Natl Acad Sci U S A 94: 2569-74. doi:

Cadenhead KS, Swerdlow NR, Shafer KM, Diaz M, Braff DL (2000) Modulation of the startle response and startle laterality in relatives of schizophrenic patients and in subjects with schizotypal personality disorder: evidence of inhibitory deficits. Am J Psychiatry 157: 1660-8. doi:

Chen J, Lipska BK, Halim N, Ma QD, Matsumoto M, Melhem S, Kolachana BS, Hyde TM, Herman MM, Apud J, Egan MF, Kleinman JE, Weinberger DR (2004) Functional analysis of genetic variation in catechol-Omethyltransferase (COMT): effects on mRNA, protein, and enzyme activity in postmortem human brain. American journal of human genetics 75: 807-21. doi: $10.1086 / 425589$ 
Creese I, Burt DR, Snyder SH (1976) Dopamine receptor binding predicts clinical and pharmacological potencies of antischizophrenic drugs. Science (New York, NY) 192: 481-3. doi:

Dawson ME, Hazlett EA, Filion DL, Nuechterlein KH, Schell AM (1993) Attention and schizophrenia: impaired modulation of the startle reflex. Journal of abnormal psychology 102: 633-41. doi:

Dawson ME, Schell AM, Hazlett EA, Nuechterlein KH, Filion DL (2000) On the clinical and cognitive meaning of impaired sensorimotor gating in schizophrenia. Psychiatry Res 96: 187-97. doi:

Durstewitz D, Seamans JK (2008) The dual-state theory of prefrontal cortex dopamine function with relevance to catechol-o-methyltransferase genotypes and schizophrenia. Biol Psychiatry 64: 739-49. doi: 10.1016/j.biopsych.2008.05.015

Ekman P, Friesen WV, Simons RC (1985) Is the startle reaction an emotion? Journal of personality and social psychology 49: 1416-26. doi:

Floderus Y, Ross SB, Wetterberg L (1981) Erythrocyte catechol-O-methyltransferase activity in a Swedish population. Clinical genetics 19: 389-92. doi:

Foss JA, Ison JR, Torre JP, Jr., Wansack S (1989) The acoustic startle response and disruption of aiming: II. Modulation by forewarning and preliminary stimuli. Human factors 31: 319-33. doi:

Gelman A, Carlin J, HS. S, DB. R (2003) Bayesian data analysis. Chapman and Hall, London

Gelman A, Rubin D (1992) Inference from Integrative Stimulation Using Multiple Sequences. Statistical Science 7: 457 - 472. doi:

Glenthoj BY, Mackeprang T, Svarer C, Rasmussen H, Pinborg LH, Friberg L, Baare W, Hemmingsen R, Videbaek C (2006) Frontal dopamine $\mathrm{D}(2 / 3)$ receptor binding in drug-naive first-episode schizophrenic patients correlates with positive psychotic symptoms and gender. Biol Psychiatry 60: 621-9. doi: 10.1016/j.biopsych.2006.01.010

Hadfield J (2010) MCMC Methods for Multi-Response Generalized Linear Mixed Models: The MCMCglmm R Package. Journal of Statistical Software 33: 122. doi:

Howes OD, Kapur S (2009) The dopamine hypothesis of schizophrenia: version III-the final common pathway. Schizophr Bull 35: 549-62. doi: $10.1093 / \mathrm{schbul} / \mathrm{sbp} 006$

Hutchison KE, Swift R (1999) Effect of d-amphetamine on prepulse inhibition of the startle reflex in humans. Psychopharmacology (Berl) 143: 394-400. doi:

Kaasinen V, Nagren K, Hietala J, Farde L, Rinne JO (2001) Sex differences in extrastriatal dopamine $\mathrm{d}(2)$-like receptors in the human brain. Am J Psychiatry 158: 308-11. doi:

Kedzior KK, Martin-Iverson MT (2007) Attention-dependent reduction in prepulse inhibition of the startle reflex in cannabis users and schizophrenia patients--a pilot study. European journal of pharmacology 560: 176-82. doi: 10.1016/j.ejphar.2007.01.032

Kumakura Y, Cumming P, Vernaleken I, Buchholz HG, Siessmeier T, Heinz A, Kienast T, Bartenstein P, Grunder G (2007) Elevated [18F]fluorodopamine turnover in brain of patients with schizophrenia: an [18F]fluorodopa/positron emission tomography study. The Journal of neuroscience : the official journal of the Society for Neuroscience 27: 8080-7. doi: 10.1523/jneurosci.080507.2007 
Kumari V, Aasen I, Sharma T (2004) Sex differences in prepulse inhibition deficits in chronic schizophrenia. Schizophr Res 69: 219-35. doi:

Laakso A, Vilkman H, Bergman J, Haaparanta M, Solin O, Syvalahti E, Salokangas RK, Hietala J (2002) Sex differences in striatal presynaptic dopamine synthesis capacity in healthy subjects. Biol Psychiatry 52: 759-63. doi:

Laruelle M, Abi-Dargham A, van Dyck CH, Gil R, D'Souza CD, Erdos J, McCance E, Rosenblatt W, Fingado C, Zoghbi SS, Baldwin RM, Seibyl JP, Krystal JH, Charney DS, Innis RB (1996) Single photon emission computerized tomography imaging of amphetamine-induced dopamine release in drug-free schizophrenic subjects. Proc Natl Acad Sci U S A 93: 9235-40. doi:

Mansbach RS, Geyer MA, Braff DL (1988) Dopaminergic stimulation disrupts sensorimotor gating in the rat. Psychopharmacology (Berl) 94: 507-14. doi:

Martin-Iverson MT, Else D (2000) PHNO, a selective dopamine D2 receptor agonist, does not reduce prepulse inhibition of the startle reflex in rats.

Psychopharmacology (Berl) 151: 38-48. doi:

Meloni EG, Davis M (1999) Enhancement of the acoustic startle response in rats by the dopamine D1 receptor agonist SKF 82958. Psychopharmacology (Berl) 144: 373-80. doi:

Parwani A, Duncan EJ, Bartlett E, Madonick SH, Efferen TR, Rajan R, Sanfilipo M, Chappell PB, Chakravorty S, Gonzenbach S, Ko GN, Rotrosen JP (2000) Impaired prepulse inhibition of acoustic startle in schizophrenia. Biol Psychiatry 47: 662-9. doi:

Plummer M (2013) rjags: Bayesian graphical models using MCMC.

Pohjalainen T, Rinne JO, Nagren K, Syvalahti E, Hietala J (1998) Sex differences in the striatal dopamine $\mathrm{D} 2$ receptor binding characteristics in vivo. Am J Psychiatry 155: 768-73. doi:

Riccardi P, Zald D, Li R, Park S, Ansari MS, Dawant B, Anderson S, Woodward N, Schmidt D, Baldwin R, Kessler R (2006) Sex differences in amphetamineinduced displacement of $[(18) \mathrm{F}]$ fallypride in striatal and extrastriatal regions: a PET study. Am J Psychiatry 163: 1639-41. doi: 10.1176/appi.ajp.163.9.1639

Salum C, Guimaraes FS, Brandao ML, Del Bel EA (2006) Dopamine and nitric oxide interaction on the modulation of prepulse inhibition of the acoustic startle response in the Wistar rat. Psychopharmacology (Berl) 185: 133-41. doi: $10.1007 / \mathrm{s} 00213-005-0277-\mathrm{z}$

Scholes KE, Martin-Iverson MT (2009) Relationships between prepulse inhibition and cognition are mediated by attentional processes. Behavioural brain research 205: 456-67. doi: 10.1016/j.bbr.2009.07.031

Scholes KE, Martin-Iverson MT (2010) Disturbed prepulse inhibition in patients with schizophrenia is consequential to dysfunction of selective attention.

Psychophysiology 47: 223-35. doi: 10.1111/j.1469-8986.2009.00927.x

Seeman P, Chau-Wong M, Tedesco J, Wong K (1975) Brain receptors for antipsychotic drugs and dopamine: direct binding assays. Proc Natl Acad Sci U S A 72: 4376-80. doi:

Seeman P, Lee T (1975) Antipsychotic drugs: direct correlation between clinical potency and presynaptic action on dopamine neurons. Science (New York, NY) 188: 1217-9. doi:

Swerdlow NR, Eastvold A, Karban B, Ploum Y, Stephany N, Geyer MA, Cadenhead K, Auerbach PP (2002) Dopamine agonist effects on startle and sensorimotor gating in normal male subjects: time course studies. Psychopharmacology 
(Berl) 161: 189-201. doi: 10.1007/s00213-002-1040-3

Swerdlow NR, Geyer MA, Hartman PL, Sprock J, Auerbach PP, Cadenhead K, Perry W, Braff DL (1999) Sex differences in sensorimotor gating of the human startle reflex: all smoke? Psychopharmacology (Berl) 146: 228-32. doi:

Swerdlow NR, Light GA, Cadenhead KS, Sprock J, Hsieh MH, Braff DL (2006) Startle gating deficits in a large cohort of patients with schizophrenia: relationship to medications, symptoms, neurocognition, and level of function. Arch Gen Psychiatry 63: 1325-35. doi: 10.1001/archpsyc.63.12.1325

Swerdlow NR, Mansbach RS, Geyer MA, Pulvirenti L, Koob GF, Braff DL (1990) Amphetamine disruption of prepulse inhibition of acoustic startle is reversed by depletion of mesolimbic dopamine. Psychopharmacology (Berl) 100: 4136. doi:

Swerdlow NR, Stephany N, Wasserman LC, Talledo J, Shoemaker J, Auerbach PP (2003) Amphetamine effects on prepulse inhibition across-species: replication and parametric extension. Neuropsychopharmacology 28: 640-50. doi: 10.1038/sj.npp.1300086

Talledo JA, Sutherland Owens AN, Schortinghuis T, Swerdlow NR (2009) Amphetamine effects on startle gating in normal women and female rats. Psychopharmacology (Berl) 204: 165-75. doi: 10.1007/s00213-008-1446-7

Turetsky BI, Calkins ME, Light GA, Olincy A, Radant AD, Swerdlow NR (2007) Neurophysiological endophenotypes of schizophrenia: the viability of selected candidate measures. Schizophr Bull 33: 69-94. doi: 10.1093/schbul/sb1060

Wan FJ, Swerdlow NR (1993) Intra-accumbens infusion of quinpirole impairs sensorimotor gating of acoustic startle in rats. Psychopharmacology (Berl) 113: 103-9. doi: 
Tables

Table 1

\begin{tabular}{|c|c|c|c|c|c|}
\hline & $\begin{array}{c}\text { Drug order } 1 \\
\left(\text { PLA } 1^{\text {st }}\right)\end{array}$ & 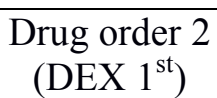 & $t / \chi^{2}$ & $\mathrm{p}$ & Overall \\
\hline Mean age (SD) & & & & & $23.0(4.9)$ \\
\hline Mean Weight (SD) & & & & & $74.6(13.9)$ \\
\hline $\operatorname{Sex}(\mathrm{F} \mid \mathrm{M})$ & $(11 \mid 22)$ & $(13 \mid 18)$ & 0.20 & 0.65 & $24 \mid 40$ \\
\hline Attorder (ATT $1^{\text {st }} \mid$ IG $\left.1^{\text {st }}\right)$ & $(15 \mid 18)$ & $(15 \mid 16)$ & 0.00 & 1.00 & \begin{tabular}{l|l|}
30 & 34 \\
\end{tabular} \\
\hline Amph Use (N|Y) & $(19 \mid 14)$ & $(19 \mid 12)$ & 0.00 & 0.96 & $38 \mid 26$ \\
\hline Curr Smoker $(\mathrm{N} \mid \mathrm{Y})$ & $(28 \mid 5)$ & $(23 \mid 8)$ & 0.56 & 0.45 & \begin{tabular}{l|l}
51 & 13
\end{tabular} \\
\hline
\end{tabular}

PLA $1^{\text {st }}$, placebo in first session; DEX $1^{\text {st }}$, dexamphetamine in first session; Attorder, order of attention conditions; ATT $1^{\text {st }}$, attend condition first; IG $1^{\text {st }}$, ignore condition first; Amph use, ever used amphetamines; curr smoker; current smoker.

\section{Figure legends}

\section{Fig 1}

Startle only curves (right) and contrasts (left) illustrating the effect of dexamphetamine (A), sex (B), and the interaction between drug and sex (C). Solid curves (right) were generated from the mean parameter estimates $( \pm 95 \%$ highest density intervals, as indicated by the dashed curves) that were obtained from the each of the respective mixed-effects models for $\mathrm{R}_{\mathrm{MAX}}, \mathrm{ES}_{50}$, and hillslope. Small dots indicate the average startle magnitudes for each stimulus amplitude and for each participant during the respective experimental conditions. The contrasts (left) for each startle only parameter are dexamphetamine - placebo (A), female - male (B), and the drug by sex interaction [dexamphetamine FEMALE $_{\text {- }}$ placebo ${ }_{\text {FEMALE }}$ ] -

[dexamphetamine MALE $_{\text {- placebo }}$ MALE $](C) n=64$

\section{Fig 2}

Main effects of drug (top: $\mathrm{Pl}=$ Placebo, $\mathrm{Dx}=$ Dexamphetamine), Attention $\left(2^{\text {nd }}\right.$ from top: At $=$ Attend, $I g=$ Ignore $),$ Sex $\left(2^{\text {nd }}\right.$ from bottom: $M=$ Male, $F=$ Female $)$, and SOA (bottom: $60=60 \mathrm{~ms}$ SOA, $100=100 \mathrm{~ms}$ SOA) on PPI of $\mathrm{R}_{\mathrm{MAX}}$ (leftmost column), $\mathrm{ES}_{50}\left(2^{\text {nd }}\right.$ from left), threshold ( $2^{\text {nd }}$ from right), and $\log _{10}$ hillslope (rightmost column). Large open circles ( \pm error bars) indicate the mean parameter estimate $( \pm$ $95 \% \mathrm{HDI}$ ) obtained from the posterior of the mixed-effects model. Contrasts indicate the difference in the posterior estimates between the respective main effects factors. Small circles depict the average of the raw data over each of the respective main effects factors, or the difference between main effects factors for the contrast estimates (except for Sex, which is a between subjects factor so there are no raw difference scores)

\section{Fig 3}

Drug by Attend interaction for the PPI of $\mathrm{R}_{\mathrm{MAX}}$ (leftmost column), $\mathrm{ES}_{50}\left(2^{\text {nd }}\right.$ from left), threshold ( $2^{\text {nd }}$ from right), and $\log _{10}$ hillslope (rightmost column). The top row presents the means ( $\pm 95 \%$ HDIs) obtained from the posterior of the mixed-effects model for each drug by attention condition (top row). The bottom row presents the contrasts for Attend - Ignore for Placebo (Pl), Attend - Ignore for Dexamphetamine (Dx) and the interaction between drug and attention (Drug*Att $=$ Dx[At-Ig] - Pl[AtIg]) 
Supplementary Material 1:

This is a script for the " $\mathrm{R}$ " package which evaluates non-linear least squares estimation versus a Hierarchical Bayesian method for fitting sigmoidal curves for startle data as used in the present paper. Parameters are simulated from random uniform distributions that have upper and lower limits appropriate for each parameter. The parameters obtained from the Hierarchical Bayesian method consistently show less deviation from the simulated parameters compared to the least squares fits

\section{Supplementary Material 2}

A random selection of three parameter Sigmoidal fits (see paper and Supplementary Material 1 for formula) from the Bayesian nonlinear hierarchical model to show the goodness of fit to the startle and PPI data. Each box represents one individual's fits for one prepulse condition (either no prepulse, $60 \mathrm{~ms}$ SOA or $100 \mathrm{~ms}$ SOA) across each of the drug (placebo and dexmaphetamine) and attention (Attend and Ignore) conditions. A total of 80 sigmoidal curves are shown. Raw data (circles) and the fitted function (solid lines). See Supplementary Material for a script simulating startle data and fitting the Bayesian model with a comparison to least squares fits

Supplementary Material 3

Tables showing the means ( $\pm 95 \%$ HDI) and contrasts ( $\pm 95 \%$ HDI) for Startle only (Table 1) and PPI (Table 2). All parameter estimates and contrasts were obtained from the mixed-effects models 
A

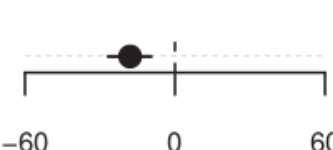

Rmax (uV)

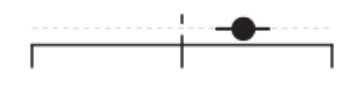

$\begin{array}{lll}-6 & 0 & 6\end{array}$

ES50 (dB)

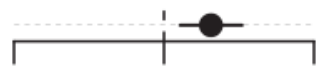

Threshold (dB)

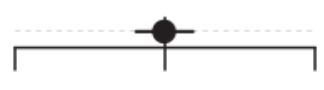

$\begin{array}{lll}-0.4 & 0 & 0.4\end{array}$

Contrast

Contrast
xamp - Placebo

\section{Dexamp - Placebo}

27

29

32

34

36

37

38

39
40

40

42

43
44
45

46
47

48

49

50

51

5

53

55

56

57

58

60

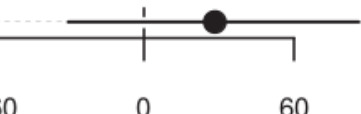

$R \max (\mathrm{uV})$

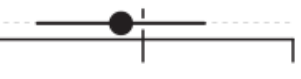

ES50 (dB)

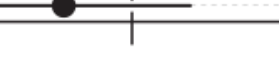

Threshold (dB)

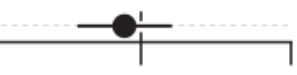

Contrast

Female - Male

C

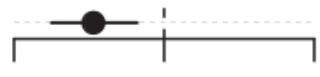

$-60$

$R \max (\mathrm{uV})$
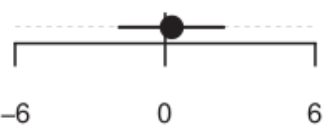

ES50 (dB)

Threshold (dB)

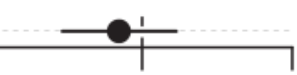

$-0.4$

log10 Hillslope

Interaction

(F.D-F.P)-(M.D-M.P)

\section{xamphetamine}





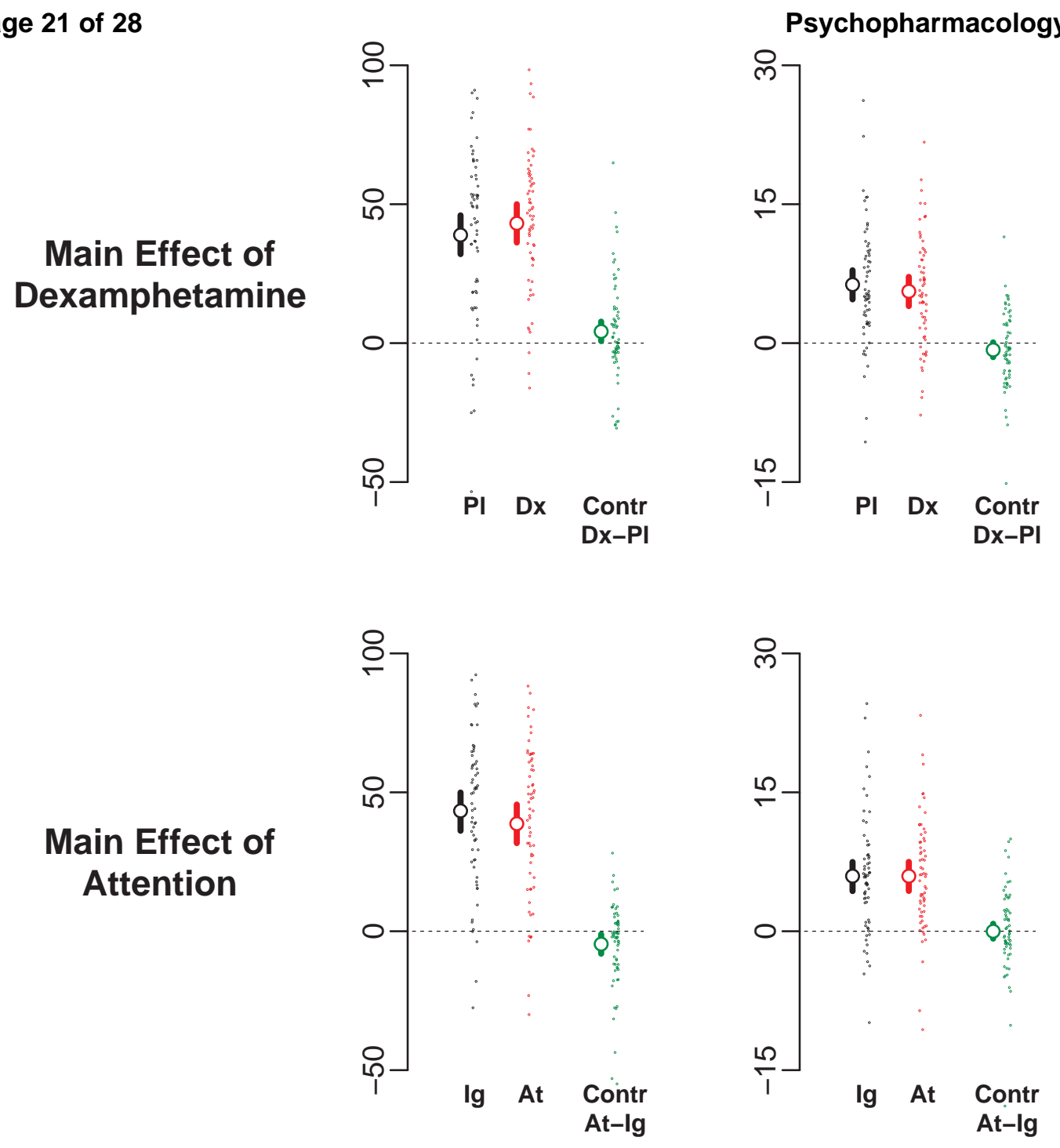
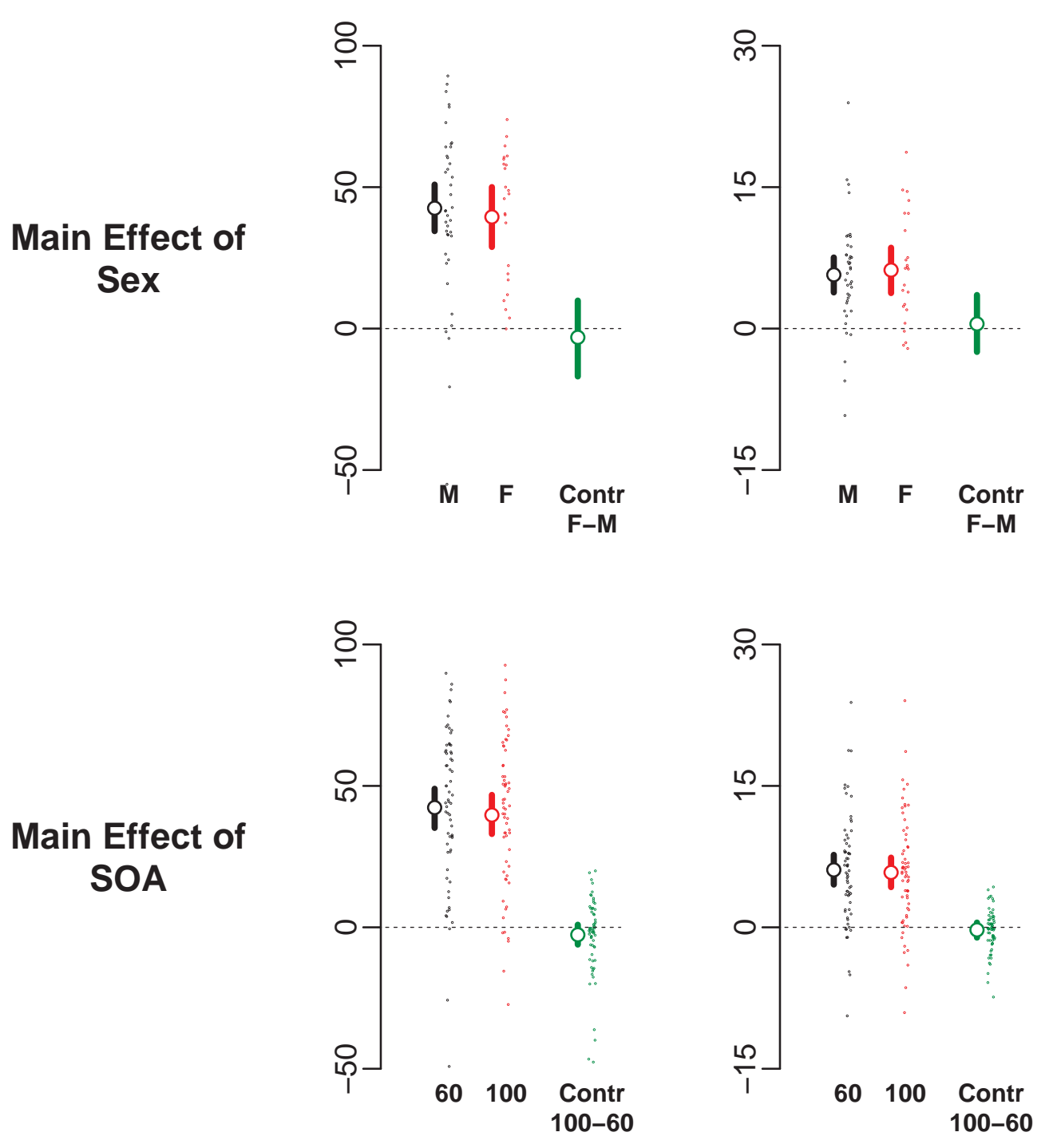

\section{Main Effect of} Attention

\section{Main Effect of} Sex
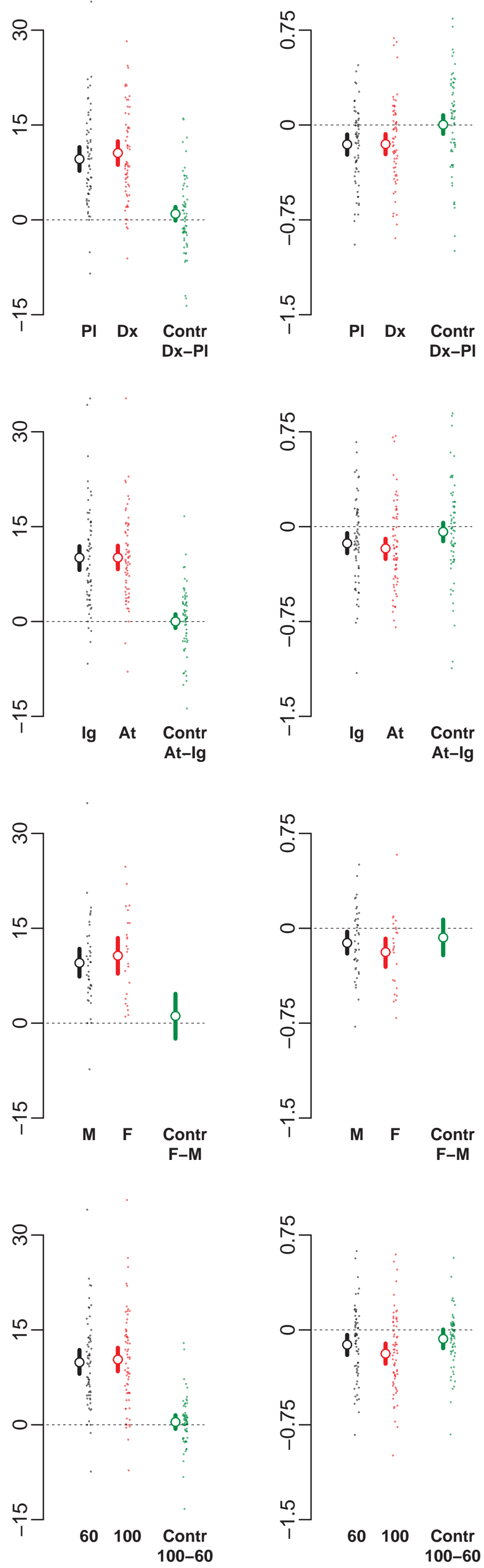

PPI of Rmax (\%) 


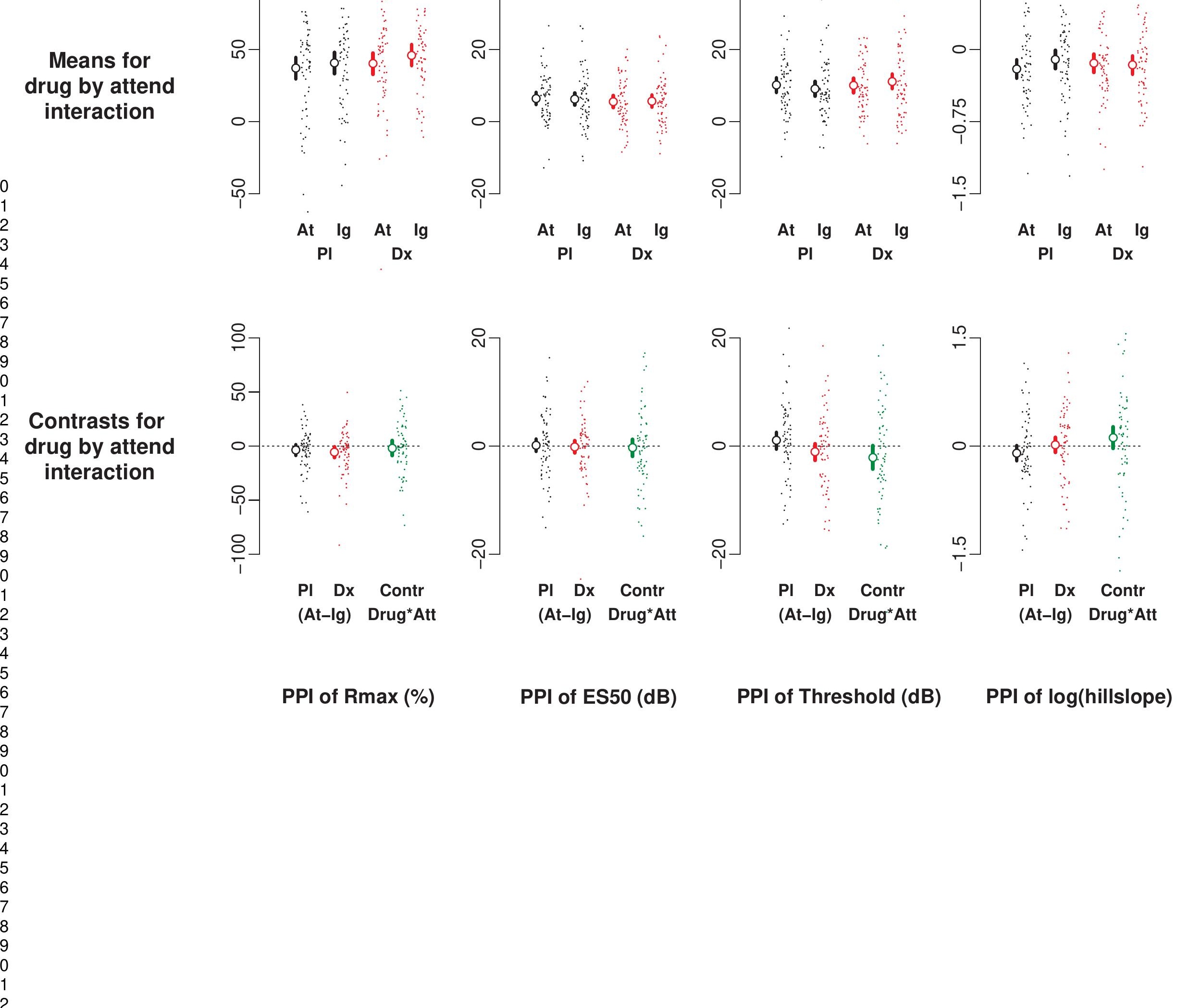


Supplementary Material 1

\#\#\#\# Non-linear fits

\#\#\#\# least squares vs hierarchical Bayes

require(rjags); require(data.table)

\# Curve Fitting Functions

nlscurve $<-$ function $(\mathrm{x}, \mathrm{y})\{$

fits $<-n l s\left(\mathrm{y} \sim \mathrm{U}+(\mathrm{y} 0-\mathrm{U}) /\left(1+(\mathrm{x} / \mathrm{ES} 50)^{\wedge}\right.\right.$ hillslope $)$,

start = list("U" = 100, "y0" = 0, "ES50" = 100, "hillslope" = 10),

lower = list("U" = 0, "y0" = 0, "ES50" = 79, "hillslope" = 2),

upper = list ("U" = maxUP,"y0" = 0, "ES50" = 116, "hillslope" = 500), control = nls.control(warnOnly = TRUE, maxiter=1000),

algorithm = "port")

\}

bayescurve $<-$ function ()\{

modeltext $="$

model \{

for(j in 1:yl)\{

for(i in 1:xl)\{

$\mathrm{y}[\mathrm{i}, \mathrm{j}] \sim \operatorname{dnorm}(\mathrm{mu}[\mathrm{i}, \mathrm{j}]$, tau $)$

$\mathrm{mu}[\mathrm{i}, \mathrm{j}]<-\operatorname{upAsym}[\mathrm{j}]+(0-\operatorname{upAsym}[\mathrm{j}]) /\left(1+(\mathrm{x}[\mathrm{i}] / \mathrm{ES} 50[\mathrm{j}])^{\wedge} \mathrm{hill}[\mathrm{j}]\right)$

\}

\}

for(j in 1:yl)\{

upAsym[j] dnorm(HupAsym, asymTau)T(0, maxUP)

ES50[j] d dnorm(HES50, es50Tau)T $(79,116)$

hill[j] $\sim \operatorname{dlnorm}($ Hhill, hillTau)T(2,500)

\}

HupAsym dunif(0, maxUP)

HES50 dunif $(79,116)$

Hhill $\sim \operatorname{dunif}(0,7)$

asymTau <- pow(asymSD, -2)

es50Tau <- pow(es50SD, -2)

hillTau <- pow(hillSD, -2)

asymSD $\sim \operatorname{dt}(0,1 / 10000,1) \mathrm{T}(0$,

es50SD $\sim \operatorname{dt}(0,1 / 10000,1) \mathrm{T}(0$,

hillSD $\sim \operatorname{dt}(0,1 / 1000,1) \mathrm{T}(0$,

tau <- pow $(\mathrm{sd},-2)$

sd $\sim \operatorname{dunif}(0,1000)$

\}

\# Write out modelString to a text file

writeLines ( modeltext , con="mod1.txt" )

parameters = c( "upAsym" , "ES50", "hill", "sd" ,

"HES50", "HupAsym", "Hhill", 
"asymSD", "es50SD", "hillSD") \# The parameters to be monitored adaptSteps $=1000 \quad$ \# Number of steps to "tune" the samplers

burnInSteps $=5000$ \#prob need this higher due to the model parameterisation nChains $=3$

numSavedSteps $=10000$ \# Also this should be larger

nIter = ceiling ( ( numSavedSteps $) /$ nChains $)$

\# Create, initialize, and adapt the model:

jagsModel $=$ jags.model $($ "mod1.txt" , data=dataList , n.chains $=$ nChains, n.adapt $=$ adaptSteps )

cat( "Burning in the MCMC chain...\n")

update( jagsModel , n.iter=burnInSteps )

cat( "Sampling final MCMC chain... $\backslash n$ ")

codaSamples = coda.samples $($ jagsModel , variable.names=parameters ,

n.iter=nIter )

mcmcChain <- as.matrix(codaSamples)

return(mcmcChain)

\}

extract $<-$ function ()\{

ls <- list()

for $(\mathrm{j}$ in $1: \mathrm{yl})\{$

ls $[[j]]<-\operatorname{sigcurve}(\mathrm{x}, \mathrm{y}[\mathrm{j}]])$

\}

hillN <- sapply(1:yl, function(j) coef(ls[[j]])[4])

ES50N <- sapply(1:yl, function(j) coef(ls[[j]])[3])

upAsymN <- sapply(1:yl, function(j) coef(ls[[j]])[1])

hillB <- sapply(1:yl, function(j) median(mcmcChain[, paste0("hill[", j, "]")])) upAsymB <- sapply(1:yl, function(j) median(mcmcChain[, paste0("upAsym[", j, "]")]))

ES50B <- sapply(1:yl, function(j) median(mcmcChain[, paste0("ES50[", j, "]")]))

aa <- cbind(upAsym, upAsymB, upAsymN, ES50, ES50B, ES50N, hill, hillB, hillN) rownames(aa) <- 1:yl

return(aa)

\}

\# Simulation

$\mathrm{k}<-1000$

$\mathrm{x}<-\operatorname{seq}(80,115,5) \quad$ \# Startling stimuli intensities

$\mathrm{xl}<-\operatorname{length}(\mathrm{x})$

yl $<-4 \quad$ \# Number of experimental conditions

difs <- matrix(0, nrow=k, ncol=12) \# Output for diffences between nls and

Bayes

for(R in $1: \mathrm{k})\{$

\#Data

upAsym <- runif(yl, $\min =5, \max =500)$ \# Sample parameters from

ES50 <- runif(yl, $\min =75, \max =120$ ) \# a uniform distribution 
hill <- $\operatorname{runif}(\mathrm{yl}, \min =2, \max =500)$

$\mathrm{y}<-\operatorname{matrix}(0$, nrow $=x l$, ncol $=y l)$

for(j in 1:yl)\{ \# Create y data

$y[j]<-\operatorname{upAsym}[\mathrm{j}]+(0-\operatorname{upAsym}[\mathrm{j}]) /\left(1+(\mathrm{x} / \mathrm{ES} 50[\mathrm{j}])^{\wedge} \mathrm{hill}[\mathrm{j}]\right)+\operatorname{rnorm}(\mathrm{xl}$, $0,20)$

$\mathrm{y}[\mathrm{y}[\mathrm{j}]<0, \mathrm{j}]<-0$

\}

$\max U P=\max (y) * 1.5 \quad$ \# Upper limit for Rmax for each person

dataList $<-\operatorname{list}(\mathrm{x}=\mathrm{x}, \mathrm{y}=\mathrm{y}, \mathrm{xl}=\mathrm{xl}, \mathrm{yl}=\mathrm{yl}$, $\operatorname{maxUP}=\max U P)$

\#fits

mcmcChain <- bayescurve() \# Obtain Bayes fits

aa $<-$ extract $0 \quad$ \# Obtain nls fits + comparison output

aa $<-$ data.table(aa)

aa[, difAsymB := upAsymB - upAsym]

aa[, difES50B := ES50B - ES50]

aa[, difhillB := hillB - hill]

aa[, difAsymN := upAsymN - upAsym]

aa[, difES50N := ES50N - ES50]

aa[, difhillN := hillN - hill]

$\operatorname{difs}[\mathrm{R}]<,-\mathrm{c}(\operatorname{colMeans}(\mathrm{aa}[, 10: 15$, with=F]), colMeans(abs(aa[, 10:15, with=F])) \}

\# Evaluation

df1 <- data.table(difs)

setnames(df1, names(df1), c(names(aa)[10:15], paste0("a", names(aa)[10:15])))

mdifs $<-$ colMeans(df1)

mdifs $<-$ matrix(mdifs, nrow=3)

rownames(mdifs) <- c("upAsym", "ES50", "hill")

colnames(mdifs) <- c("DifB", "DifF", "absDifB", "absDifF") 
Supplementary material 2
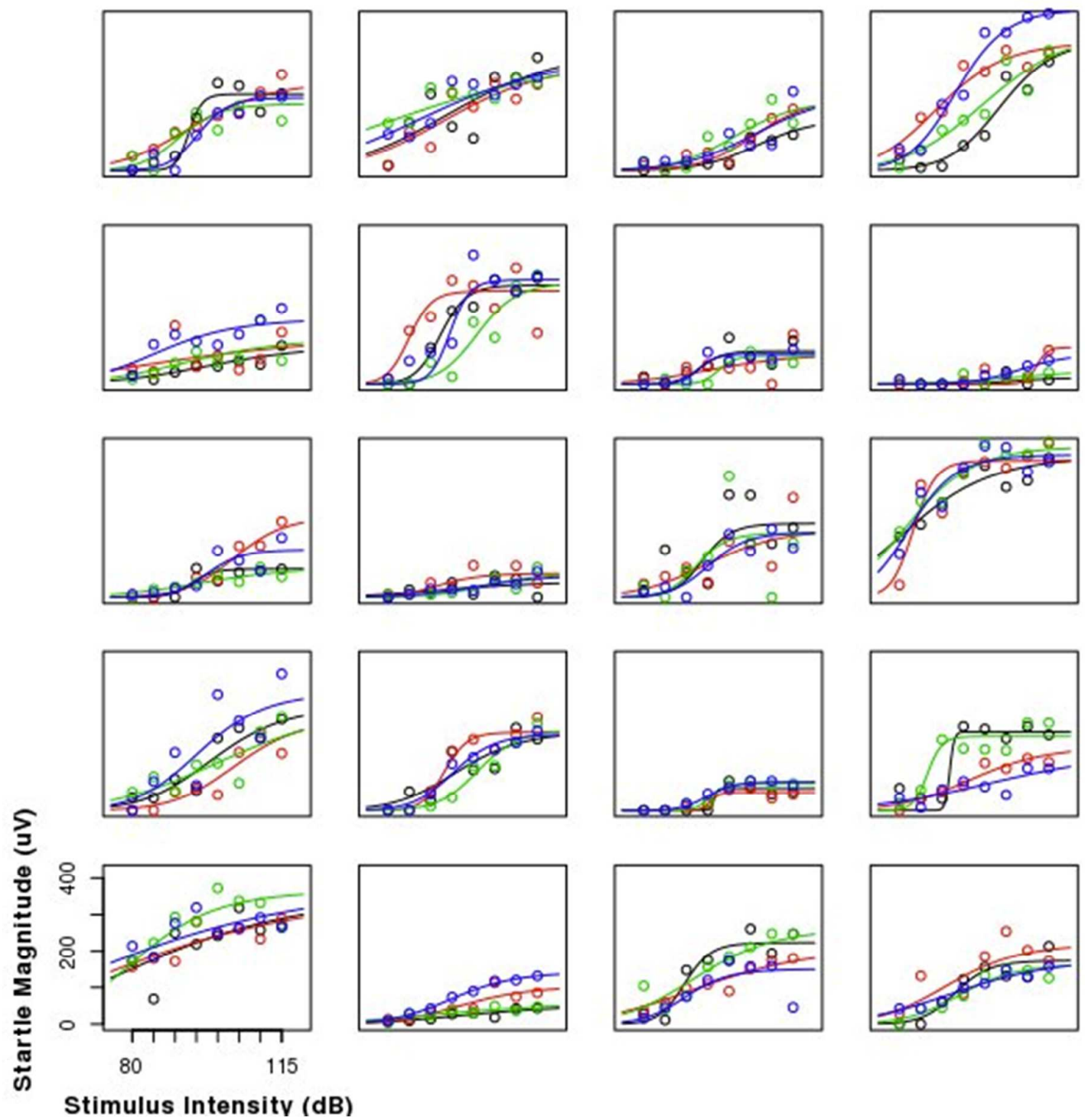

34

35

36

37

38

39

40

41

42

43

44

45

46

47

48

49

50

51

52

53

54

55

56 
Startle

Supplementary material 3

Startle only means \& Contrasts

\begin{tabular}{|c|c|c|c|c|c|c|c|c|}
\hline & Mean & $\begin{array}{l}\text { Rmax } \\
95 \% \mathrm{HDI}\end{array}$ & Mean & $\begin{array}{l}\text { ES50 } \\
95 \% \text { HDI }\end{array}$ & Mean & $\begin{array}{l}\text { Threshold } \\
95 \% \mathrm{HDI}\end{array}$ & Mean & $\begin{array}{l}\text { Hillslope } \\
95 \% \text { HDI }\end{array}$ \\
\hline \multicolumn{9}{|l|}{ Placebo } \\
\hline Female Ignore & 231.8 & $184.2,279.6$ & 94.7 & $91.6,97.7$ & 85.4 & $81.1,89.6$ & 1.34 & $1.20,1.48$ \\
\hline Female Attend & 234.5 & $185.4,280.6$ & 94.2 & $91.1,97.2$ & 82.2 & $78.0,86.4$ & 1.19 & $1.04,1.32$ \\
\hline Male Ignore & 197.3 & $160.6,233.7$ & 95.4 & $93.1,97.8$ & 86.1 & $82.7,89.3$ & 1.27 & $1.15,1.37$ \\
\hline Male Attend & 184.0 & $146.5,219.9$ & 95.6 & $93.3,98.0$ & 86.9 & $83.7,90.3$ & 1.28 & $1.17,1.39$ \\
\hline \multicolumn{9}{|l|}{ Dexamphetamine } \\
\hline Female Ignore & 197.1 & $149.0,244.5$ & 97.2 & $94.2,100.2$ & 85.4 & $81.1,89.5$ & 1.18 & $1.04,1.32$ \\
\hline Female Attend & 205.0 & $156.8,252.6$ & 97.0 & $94.0,99.9$ & 85.9 & $81.6,90.0$ & 1.28 & $1.14,1.43$ \\
\hline Male Ignore & 188.0 & $152.9,226.5$ & 97.9 & $95.6,100.2$ & 88.5 & $85.3,91.8$ & 1.30 & $1.19,1.41$ \\
\hline Male Attend & 185.7 & $149.7,223.1$ & 97.8 & $95.4,100.1$ & 88.3 & $85.1,91.6$ & 1.30 & $1.20,1.41$ \\
\hline \multicolumn{9}{|l|}{ Contrasts } \\
\hline Drug (Dex - Placebo) & -18.0 & $-26.7,-9.54$ & 2.46 & $1.39,3.46$ & 1.88 & $0.65,3.12$ & -0.002 & $-0.077,0.074$ \\
\hline Attention (Att - lg) & -1.21 & $-9.65,7.35$ & -0.17 & $-1.23,0.84$ & -0.49 & $-1.75,0.68$ & -0.006 & $-0.083,0.070$ \\
\hline $\operatorname{Sex}(F-M)$ & 28.4 & $-30.3,85.9$ & -0.88 & $-4.23,2.46$ & -2.73 & $-7.51,2.33$ & -0.044 & $-0.17,0.079$ \\
\hline Drug * Attend & 8.16 & $-9.19,25.3$ & 0.02 & $-2.04,2.09$ & 1.26 & $-1.16,3.69$ & 0.121 & $-0.033,0.27$ \\
\hline Drug * Sex & -28.3 & $-44.9,-10.9$ & 0.26 & $-1.83,2.34$ & -0.07 & $-2.51,2.36$ & -0.062 & $-0.21,0.091$ \\
\hline Attend * Sex & 13.1 & $-4.79,29.7$ & -0.34 & $-2.47,1.68$ & -1.65 & $-4.17,0.72$ & -0.033 & $-0.19,0.12$ \\
\hline Attend * Sex * Drug & -5.27 & $-33.3,21.1$ & -0.34 & $-3.64,2.87$ & -3.64 & $-7.46,0.15$ & -0.257 & $-0.49,-0.012$ \\
\hline
\end{tabular}

Page 1 
PPI

PPI means \& Contrasts

\begin{tabular}{|c|c|c|c|c|c|c|c|c|}
\hline & \multicolumn{2}{|r|}{$\mathrm{Rmax}$} & \multicolumn{2}{|r|}{ ES50 } & \multicolumn{2}{|r|}{ Threshold } & \multicolumn{2}{|r|}{ Hillslope } \\
\hline & Mean & $95 \% \mathrm{HDI}$ & Mean & $95 \% \mathrm{HDI}$ & Mean & $95 \% \mathrm{HDI}$ & Mean & $95 \% \mathrm{HDI}$ \\
\hline \multicolumn{9}{|l|}{ Placebo } \\
\hline Female Ignore 60 & 41.0 & $28.1,53.9$ & 7.23 & $4.32,10.2$ & 8.66 & $5.03,12.3$ & -0.01 & $-0.20,0.18$ \\
\hline Female Ignore 100 & 38.3 & $25.5,51.3$ & 6.69 & $3.75,9.64$ & 9.73 & $6.17,13.4$ & -0.17 & $-0.35,0.026$ \\
\hline Female Attend 60 & 36.4 & $23.8,49.3$ & 6.80 & $3.81,9.64$ & 11.20 & $7.47,14.8$ & -0.30 & $-0.49,-0.11$ \\
\hline Female Attend 100 & 36.9 & $24.0,49.8$ & 6.15 & $3.30,9.12$ & 10.50 & $6.88,14.1$ & -0.24 & $-0.43,-0.051$ \\
\hline Male Ignore 60 & 44.1 & $34.4,54.1$ & 5.86 & $3.63,8.14$ & 9.07 & $6.24,11.8$ & -0.05 & $-0.19,0.11$ \\
\hline Male Ignore 100 & 39.5 & $29.7,49.4$ & 5.23 & $3.07,7.58$ & 8.88 & $6.01,11.6$ & -0.19 & $-0.33,-0.036$ \\
\hline Male Attend 60 & 41.0 & $31.0,51.0$ & 6.25 & $4.04,8.51$ & 9.03 & $6.24,11.9$ & -0.11 & $-0.26,0.036$ \\
\hline Male Attend 100 & 34.1 & $24.3,44.3$ & 6.38 & $4.16,8.66$ & 9.88 & $7.08,12.7$ & -0.15 & $-0.30,-0.0084$ \\
\hline \multicolumn{9}{|l|}{ Dexamphetamine } \\
\hline Female Ignore 60 & 44.0 & $31.0,56.6$ & 5.62 & $2.81,8.68$ & 11.6 & $8.10,15.3$ & -0.18 & $-0.37,0.0055$ \\
\hline Female Ignore 100 & 43.3 & $30.4,56.0$ & 5.59 & $2.66,8.56$ & 12.5 & $9.01,16.2$ & -0.29 & $-0.48,-0.10$ \\
\hline Female Attend 60 & 38.1 & $25.7,51.4$ & 5.31 & $2.34,8.20$ & 10.4 & $6.89,14.1$ & -0.15 & $-0.34,0.035$ \\
\hline Female Attend 100 & 37.8 & $24.9,50.4$ & 6.27 & $3.42,9.25$ & 10.7 & $7.17,14.4$ & -0.16 & $-0.34,0.043$ \\
\hline Male Ignore 60 & 47.8 & $37.9,57.8$ & 6.23 & $3.93,8.44$ & 10.1 & $7.21,12.8$ & -0.04 & $-0.19,0.099$ \\
\hline Male Ignore 100 & 48.7 & $38.7,58.6$ & 5.23 & $3.01,7.55$ & 10.2 & $7.37,13.0$ & -0.12 & $-0.27,0.031$ \\
\hline Male Attend 60 & 46.2 & $36.3,56.2$ & 5.45 & $3.15,7.66$ & 8.92 & $6.07,11.6$ & -0.09 & $-0.23,0.063$ \\
\hline Male Attend 100 & 39.1 & $29.0,48.9$ & 5.03 & $2.75,7.27$ & 10.2 & $7.33,12.9$ & -0.17 & $-0.32,-0.027$ \\
\hline \multicolumn{9}{|l|}{ Contrasts } \\
\hline Drug (Dex - Placebo) & 4.20 & $0.746,7.74$ & -0.73 & $-1.51,0.080$ & 0.96 & $-0.12,2.04$ & 0.00 & $-0.071,0.078$ \\
\hline Attend $($ Att $-\mathrm{lg})$ & -4.61 & $-8.07,-1.13$ & 0.00 & $-0.80,0.81$ & 0.01 & $-1.03,1.15$ & -0.04 & $-0.12,0.031$ \\
\hline SOA $(100-60)$ & -2.62 & $-6.08,0.911$ & -0.27 & $-1.09,0.499$ & 0.44 & $-0.66,1.51$ & -0.07 & $-0.15,0.0032$ \\
\hline $\operatorname{Sex}(F-M)$ & -3.10 & $-16.9,9.88$ & 0.50 & $-2.47,3.56$ & 1.14 & $-2.45,4.64$ & -0.07 & $-0.21,0.068$ \\
\hline Drug * Attend & -2.02 & $-8.77,5.15$ & -0.29 & $-1.90,1.25$ & -2.13 & $-4.26,0.086$ & 0.12 & $-0.032,0.27$ \\
\hline Drug * Sex & -3.12 & $-9.88,4.05$ & -0.57 & $-2.16,1.03$ & 0.66 & $-1.52,2.83$ & -0.03 & $-0.18,0.12$ \\
\hline Drug * SOA & 1.60 & $-5.50,8.44$ & 0.30 & $-1.28,1.89$ & 0.41 & $-1.79,2.55$ & 0.00 & $-0.15,0.15$ \\
\hline Attend * Sex & 0.59 & $-6.34,7.63$ & -0.29 & $-1.92,1.28$ & 0.10 & $-2.02,2.33$ & -0.01 & $-0.16,0.14$ \\
\hline Attend * SOA & -1.68 & $-8.80,5.15$ & 0.56 & $-1.10,2.12$ & -0.05 & $-2.18,2.20$ & 0.10 & $-0.043,0.25$ \\
\hline $\mathrm{Sex} * \mathrm{SOA}$ & 3.62 & $-3.33,10.5$ & 0.41 & $-1.24,1.98$ & -0.12 & $-2.23,2.05$ & 0.03 & $-0.12,0.18$ \\
\hline Attend * Sex * Drug & 2.66 & $-8.44,13.6$ & -0.68 & $-3.18,1.80$ & 3.21 & $-0.31,6.62$ & -0.27 & $-0.51,-0.036$ \\
\hline Attend * Drug * SOA & 4.17 & $-5.73,14.0$ & 0.06 & $-2.14,2.37$ & 1.78 & $-1.23,4.96$ & -0.06 & $-0.28,0.14$ \\
\hline
\end{tabular}

